\title{
The Reactive Carbonyl Derivatives of Proteins, Methylglyoxal, and Malondialdehyde in Blood of Women with Breast Cancer
}

Sabina Zhumakayeva*iD, Larissa Muravlyova, Valentina Sirota, Vilen Molotov-Luchansky, Ryszhan Bakirova, Nailya Kabildina, Xeniya Mkhitaryan (D), Zhumakayeva Ainura

Department of Oncology and Radiation Diagnostics, School of Medicine, Karaganda Medical University, Karaganda, Kazakhstan

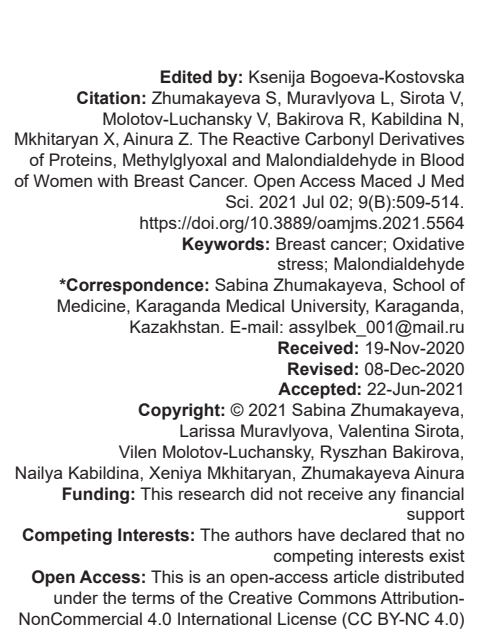

Abstract

BACKGROUND: Every year 1.5 million women in the world are diagnosed with breast cancer (BC). In 2018, more than 260,000 new cases of cancer and more than 40,000 deaths due to this disease were detected. At the same time, in Kazakhstan, an intensive indicator of the incidences of BC in 2018 amounted to $25.3 \%$ per population of 100 thousand people (2017-24.5\%) with a growth rate of $3.1 \%$, which in absolute numbers are 4,648 new cases per year. In terms of mortality, $\mathrm{BC}$ ranks third after lung and stomach cancer (6.8\%)

AIM: This necessitates a detailed study of the molecular mechanisms that underlie the development and progression of BC. One of the mechanisms of carcinogenesis is oxidative stress (OS). An increase in malondialdehyde (MDA) levels was detected in the early stages of cancer. It was suggested that MDA, due to its high cytotoxicity, acts as a promoter of the tumor and cocarcinogen agent.

METHODS: Therefore, violation of the parameters of OS in BC is in no doubt. However, according to the literature data analysis, these results are ambiguous and contradictory. There are no studies on a comprehensive assessment of the oxidative destruction of lipids, proteins, and nucleic acids in BC.

CONCLUSION: The nature and direction of changes in various components of $\mathrm{OS}$ in patients with $\mathrm{BC}$ have not been adequately studied, which is necessary for a correct assessment of the involvement of OS in the mechanism of the pathological process and determination of a sensitive marker of the risk of $\mathrm{BC}$ or its progression.

\section{Introduction}

Every year 1.5 million women in the world are diagnosed with breast cancer (BC). In 2018, more than 260,000 new cases of cancer and more than 40,000 deaths due to this disease were detected [1].

At the same time, in Kazakhstan, an intensive indicator of the incidences of BC in 2018 amounted to $25.3 \%$ per population of 100 thousand people (2017-24.5\%) with a growth rate of $3.1 \%$, which in absolute numbers are 4,648 new cases per year. In terms of mortality, BC ranks third after lung and stomach cancer (6.8\%) [2]. This necessitates a detailed study of the molecular mechanisms that underlie the development and progression of $\mathrm{BC}$. One of the mechanisms of carcinogenesis is oxidative stress (OS).

OS is a complex multicomponent process of the formation of free radicals (FR), their neutralization and utilization [3]. Excessive generation of FR leads to damage of the structure and function of lipids lipid peroxidation (LP) [4], proteins (oxidative modification of proteins) [5], carbohydrates (oxidative degradation of carbohydrates), and nucleic acids [6].
In a few studies on LP and antioxidant system in the blood and tumor tissue in $\mathrm{BC}$, conflicting results have been identified. Thus, the level of malondialdehyde (MDA) in the blood of women with $\mathrm{BC}$ in comparison with the healthy women was increased [7], the same [8], or reduced [9].

An increase in MDA levels was detected in the early stages of cancer. It was suggested that MDA, due to its high cytotoxicity, acts as a promoter of the tumor and cocarcinogen agent [10].

There are few studies on oxidized modified proteins in BC. Research by Rossner et al. [11] showed that the level of carbonyl derivatives (CD) of proteins increased in the blood of women with $\mathrm{BC}$. According to the authors, an increase in the level of CD in blood plasma is a marker of the risk of $\mathrm{BC}$. In this case, three proteins with a higher sensitivity to carbonylation were found. According to the authors of the study, identification of carbonylation-sensitive proteins in tumor tissue and understanding of their role in tumor progression may contribute to the development of targeted approaches to the treatment of BC [12].

In another study, growth of protein carbonyls was found in aspirated fluid from the nipple not only 
in women with $\mathrm{BC}$ but also in women with precancer compared to that in healthy individuals. According to the authors of the study, the results confirm the hypothesis of development of OS in the microenvironment of a $\mathrm{BC}$ [13].

In 2017, the results of an epidemiological study on the role of biomarkers of OS in the risk of development and prognosis of $\mathrm{BC}$ were published. Two groups of women were examined. The first group included women in the postmenstrual period, the second one - women in the premenstrual period. In women in the postmenstrual period, the risk of development of $\mathrm{BC}$ is associated with a marker of oxidative damage to DNA (8-oxodG). At the same time, the survival of women in Group 2 after the diagnosis of $\mathrm{BC}$ correlated with the direction of changes in some parameters of LP [14].

Recently, the role of dicarbonyl stress (DS) has been actively studied. DS develops with the excessive formation of various dicarbonyl metabolites (DM), which form adducts with proteins and DNA. One of the DM is methylglyoxal (MG) [15].

Studies on cell cultures of lines MDA MB 231 and MCF 7 showed that MG has a synergistic enhancement of the cytotoxic effects of doxorubicin and cisplatin [16]

A view has been proposed that MG has a pronounced antitumor effect due to a decrease in adenosine triphosphate (ATP) synthesis and limiting in the formation of FR. ATP synthesis decreases due to inhibition of glyceroaldehyde-3-phosphate dehydrogenase activity in tumor cells, as well as tissue respiration [17].

Nokin et al. - it has been shown in cell cultures that MG has the ability to enhance tumor growth and metastasis. The authors suggested that MG has a dual effect: In small doses it stimulates tumor growth, while in large doses it has the ability to inhibit tumor growth [18].

Increased expression of glyoxalase 1 confers multidrug resistance to cancer chemotherapy and is relatively high in liver, lung, and BC [19], [20].

Moreover, OS can be the main cause of damage to brain tissue, as well as in chronic inflammatory, vascular, and neurodegenerative diseases of the central nervous system, diabetes [5], [21], [22], [23].

Therefore, violation of the parameters of OS in $\mathrm{BC}$ is in no doubt. However, according to the literature data analysis, these results are ambiguous and contradictory. There are no studies on a comprehensive assessment of the oxidative destruction of lipids, proteins, and nucleic acids in BC. The nature and direction of changes in various components of OS in patients with $\mathrm{BC}$ have not been adequately studied, which is necessary for a correct assessment of the involvement of OS in the mechanism of the pathological process and determination of a sensitive marker of the risk of $\mathrm{BC}$ or its progression.

\section{Study design}

The aim of this study was to research LP, oxidative protein modification, and DS in the blood of women with BC of various stages. This study was conducted as a part of the research work on randomized post-registration multicenter clinical trials of the original drug Arglabin in the treatment of $\mathrm{BC}$ in an increased dose in 2018-2020. (Identification code AR 01/1).

The present study involved $76 \mathrm{BC}$ patients with the first diagnosed nodular form of this disease with I-III stage and histological and immunohistochemical verification, who were admitted for treatment to the regional oncological clinic of the city of Karaganda. The age of patients ranged from 30 to 80 years. In the age group of women under 40 there were seven patients $(9.2 \%)$; 41-55 years old -30 patients $(39.5 \%)$; at the age of $56-70-33$ patients (43.4\%); and aged 70 and older - six people (7.9\%). With Stage I cancer (T1N0M0) 14 patients were observed, with the second (T2NOM0; T1N1M0; and T2N1M0) and third (T1N2-3M0 and T2N2-3M0) stages - 48 and 14 patients, respectively. Half of the patients were of reproductive age; the second half was in menopause. All patients were examined before any therapeutic measures after obtaining informed agreement. The blood of ten practically healthy women of the corresponding age was as control.

Blood was collected from the cubital vein (5 $\mathrm{ml} / \mathrm{sample}$ ) and was drawn into vacutainer tubes containing heparin. Erythrocytes were separated from plasma by centrifugation and washed for three times with physiological saline. Investigations of blood samples were done within 1-2 $\mathrm{h}$ after its collection.

\section{Methods}

Research methods included determination of the toxic LP metabolite - MDA, the level of reactive CD of proteins (RCDP) and advanced oxidation protein products (AOPP), as well as the content MG, MDA, RCDP, and MG were determined in red blood cells (RBC) and blood plasma.

The concentration of RCDP was measured following the protocol of Levine et al. [24]. To triplicate aliquots of plasma $(0.8 \mathrm{~mL}), 0.2 \mathrm{~mL}$ of $10 \%$ trichloroacetic acid solution was added. The samples centrifuged. Then, either $1 \mathrm{~mL}$ of $2 \mathrm{M} \mathrm{HCl}$ liquid solution or $10 \mathrm{~mL}$ of 2.4-dinitrophenylhydrazine (DNPH) in $2 \mathrm{M} \mathrm{HCl}$ solution was added to the precipitates, and further this mixture was incubated at $37^{\circ} \mathrm{C}$ for $90 \mathrm{~min}$. Next the samples were centrifuged again $(8,000 \mathrm{rpm}, 10 \mathrm{~min})$ and the DNPH excess was removed with ethanol-ethyl acetate $1: 1(\mathrm{v} / \mathrm{v})$. Finally, the samples were re-suspended in $6 \mathrm{M}$ of guanidine hydrochloride. Quantification was 
performed using a spectrophotometer PD - 303 UV APEL (Japan) at a $366 \mathrm{~nm}$ absorbance. Concentration of $C D$ was calculated using the molar absorption coefficient of $22,000 \mathrm{~mol}^{-1} \mathrm{~cm}^{-1}$, RCDP values were given in $\mathrm{nmol} / \mathrm{ml}$.

MG was determined by reaction with DNPH according to a modified Racker method [25]. $25 \mu \mathrm{l}$ of blood sample with $350 \mu$ l of DNPH $(0.1 \%$ DNPH in $2 \mathrm{~N}$ $\mathrm{HCl}$ ) and then added $2.125 \mathrm{~mL}$ of distilled water to each tube. Finally, samples incubated for $15 \mathrm{~min}$ at $37^{\circ} \mathrm{C}$ and after the incubation added $1.5 \mathrm{~mL}$ of $10 \% \mathrm{NaOH}$. Absorbance for spectrophotometer was set at $576 \mathrm{~nm}$; MG levels were expressed in percent absorbance of MG.

MDA in RBCs was determined according to the protocol of Goncharenko and Latinova [26]. The washed RBC was hemolyzed with distilled water with a $1: 5$ ratio. $0.3 \mathrm{~mL}$ of hemolysate was added $0.3 \mathrm{~mL}$ of $10 \%$ phosphotungstic acid and 10 min later centrifuged the samples at $3000 \mathrm{rpm}$ for $10 \mathrm{~min}$. The resulting precipitate was washed with $1 \mathrm{~mL}$ of distilled water and centrifuged once again. Then, $3 \mathrm{~mL}$ of water and $1 \mathrm{~mL}$ of thiobarbituric acid (TBA) (80 mg of TBA in a mixture of $5 \mathrm{~mL}$ of water and $5 \mathrm{~mL}$ of acetic acid) were added to the precipitate and incubated for $60 \mathrm{~min}$ in a boiling water bath. Finally, the solution was centrifuged and tested for absorbance at spectrophotometer set at $532 \mathrm{~nm}$ against water. In the calculations, we used the molar extinction coefficient, which is $1.56 \times 10^{5} \mathrm{M}^{-1} \mathrm{~cm}^{-1}$, expressed in $\mu \mathrm{mol} / \mathrm{mL}$.

MDAin blood plasma was determined according to the protocol of Korobeinikova [27] $0.5 \mathrm{~mL}$ of blood plasma was added $5.0 \mathrm{~mL}$ of $20 \%$ phosphotungstic acid and $15 \mathrm{~min}$ later centrifuged the samples at $2500 \mathrm{rpm}$ for $15 \mathrm{~min}$. The resulting precipitate was added $2 \mathrm{~mL}$ of distilled water and centrifuged once again. Then, $2 \mathrm{~mL}$ of water and $1 \mathrm{~mL}$ of $0.8 \%$ TBA were added to the precipitate and incubated for $60 \mathrm{~min}$ in a boiling water bath. Finally, the solution was centrifuged at $6000 \mathrm{rpm}$ and tested for absorbance at spectrophotometer set at $532 \mathrm{~nm}$ and $580 \mathrm{~nm}$ against water to avoid the effect of non-lipid compounds reacting with TBA. In the calculations, we used the formula $C=0.21+26.5$ $\triangle \mathrm{D}\left(\mathrm{D}_{535}{ }^{-}{ }_{580}\right) . \mathrm{C}-$ the concentration of $\mathrm{MDA}(\mathrm{nmol} / \mathrm{ml})$.

For statistical processing, we used the procedures of mathematical statistics implemented in the application programs STATISTICA 10 and EXCEL. The significance of differences between groups of patients was determined by the Chi-square method.

\section{Results}

When studying the concentration of MDA in blood plasma, a gradual increase in its concentration from Stage I to Stage III of BC was established, and reached its maximum values in the group with Stage III of BC, so MDA plasma Me (Q25; 75) was 1.99 (1.61; 2.09) and all three groups significantly exceeded the values of the control group ( $p=0.003)$.

Plasma MG concentration was statistically significantly higher than the control group values in groups with Stages I and II of BC and amounted to $34.95 \%$ (24.8; 37.5) and 33.65\% (28.2; 43.3; $p=0.000)$, respectively. While in erythrocytes, there was a decrease in $\mathrm{MG}$ concentration with a minimum value in the group with Stage II of BC, and amounted to 18.1 (13.3; 24.6; $p=0.000)$, compared with the control group.

When studying the concentration of RCDP in plasma, a predominance of concentration was revealed in groups with Stages I and III of BC, so the median RCDP in patients with Stage I of BC was $2.46(0.94$; $8.21 ; p=0.000)$, and with Stage III of BC - 2.38 (1.56; $3.61 ; p=0.000)$. A similar trend, as in the case of $M G$, continued for RCDP, as its concentration decreased in $\mathrm{RBC}$ and reached its minimum in the group of patients with Stage III of BC and amounted to 6.0 (2.19; 6.67; $p=0.000$ ) compared with a control group (Table 1). MDA in erythrocytes and AOPP did not show significant differences in Table 1.

\section{Discussion}

Obtained data showed that in the RBC of women with $B C$, regardless of the stage of the disease, there is a simultaneous increase in MDA (toxic product of LP), RCDP (which indicates an increase in the processes of oxidative modification of proteins), and MG (one of the metabolites of DS), with the highest level of MG, as well as AOPP, is observed in patients with Stage III, which indicates the prevalence of the tumor process. In the $\mathrm{RBC}$ of women with $\mathrm{BC}$, regardless of the stage of the disease, there was a significant decrease in RCDP with a significant increase in MG. There were no significant differences in the level of MDA in the RBC of women with $B C$ of varying severity.

Excessive reactive oxygen species (ROS) in $B C$ is due to a number of factors associated with dysregulation of enzymes such as NADPH-oxidase, thymidine phosphorylase and lactoperoxidase, and macrophage tumor infiltration. Macrophages produce not only ROS but also tumor necrosis factor $\alpha$, which induces intracellular OS [28], [29]. MG is also able to induce OS. ROS generation not only causes direct damage to biopolymers but also promotes the activation of intracellular signaling pathways, which also lead to overproduction of ROS [30].

In particular, extracellular matrix remodeling and activation of MG of MEK/ERK/SMAD1 of the 
Table 1: Biochemical parameters of the blood depending on the stage of $B C$

\begin{tabular}{|c|c|c|c|c|c|}
\hline Parameters & I stage; Me (Q25;Q75) & II stage; Me (Q25;Q75) & III stage; Me (Q25;Q75) & Control group; Me (Q25;Q75) & p-level \\
\hline MDA, plasma, $\mu \mathrm{mol} / \mathrm{mL}$ & $1.82(1.72 ; 1.95)$ & $1.97(1.76 ; 2.34)$ & $1.99(1.61 ; 2.09)$ & $1.05(0.79 ; 1.13)$ & 0.003 \\
\hline $\mathrm{MDA}, \mathrm{RBC}, \mu \mathrm{mol} / \mathrm{mL}$ & $7.5(27.8 ; 11.28)$ & $9.35(7.05 ; 11.73)$ & $9.10(8.97 ; 12.17)$ & $9.35(7.82 ; 10.89)$ & 0.68 \\
\hline MG, plasma $\%$ & $34.95(24.8 ; 37.5)$ & $33.65(28.2 ; 43.3)$ & $29.4(24.8 ; 43.5)$ & $0.32(0.29 ; 0.36)$ & 0.000 \\
\hline MG, RBC $\%$ & $21.7(17.8 ; 26)$ & $18.1(13.3 ; 24.6)$ & $23.98(13.3 ; 34.4)$ & $0.57(0.54 ; 0.6)$ & 0.000 \\
\hline RCDP, plasma, $\mathrm{nmol} / \mathrm{ml}$ & $2.46(0.94 ; 8.21)$ & $1.32(0.86 ; 2.34)$ & $2.38(1.56 ; 3.61)$ & $0.76(0.49 ; 1.12)$ & 0.000 \\
\hline $\mathrm{RCDP}, \mathrm{RBC}, \mathrm{nmol} / \mathrm{ml}$ & $7.47(5.48 ; 8.21)$ & $7.47(5.48 ; 8.22)$ & $6.0(2.19 ; 6.67)$ & $21.34(12.71 ; 21.64)$ & 0.000 \\
\hline AOPP & $0.24(0.21 ; 0.38)$ & $0.28(0.21 ; 0.41)$ & $0.29(0.22 ; 0.33)$ & $0.23(0.2 ; 0.32)$ & 0.63 \\
\hline
\end{tabular}

migration signaling pathways are considered as one of the mechanisms of metastasis of BC cells. The increase in MG levels, according to the literature, is due to an increase in glycolysis, which is associated with malignant transformation and cancer progression [31]. MG can form not only adducts with proteins, lipids, and nucleic acids, forming advanced glycation endproducts but also damage RBC, white blood cells, and platelets [32].

We have found that in Stage I of BC, the level of MDA is reduced comparatively to the control value; however, in Stages II and III it tends to increase. The level of RCDP and, especially MG, in plasma in BC significantly increases from Stage $\mathrm{I}$. It is noteworthy that the content of MG in blood plasma in Stage III of BC increase by 90 times compared with the control value, which undoubtedly shows the prospect of its further study as a marker of the progression and effectiveness of the therapy.

The increase in the level of RCDP in RBC requires special attention. In our opinion, this can be explained by the accumulation of oxidized proteins, mainly hemoglobin, in red cells [33]. Intracellular metabolic changes in erythrocytes associated with OS can lead to increased suicidal death of RBC [34].

Thus, obtained data showed the promise of the further study of the OS characteristics in women with $\mathrm{BC}$. In addition to understanding the mechanisms of the pathogenesis of this disease, research in this direction will provide an answer to the question of the advisability of modulating the OS as a strategy for antitumor therapy.

\section{Conclusion}

Thus, this study indicate a correlation between the stage of the tumor process and OS. Furthemore, this study demonstrated an increased production of ROS in the blood of breast cancer patients; in addition, there are high levels of MDA, MG and RCDP in the blood of these patients simultaneously. Based on the foregoing, markers MDA, MG and RCDP can be used as a diagnosis of the prevalence of the tumor process and assessment of OS.

\section{Author Contributions}

LM conceived of and designed the study, drafted the manuscript. SZ identified eligible patients. VS conceived of and designed the study. AN, XM, RB, and NK interpreted data. VML critically revised the manuscript for important intellectual content.

\section{Availability of Data and Material}

The datasets used and/or analyzed during the current study are available from the corresponding author on reasonable request.

\section{Ethical Approval and Consent to Participate}

The clinical study is conducted in accordance with ethical principles based on the Helsinki Declaration and in accordance with the requirements of the GCP and applicable law. The topic was approved at a meeting of the Central Commission on Ethics under the Ministry of Health of the Republic of Kazakhstan dated 06.06.2018 under No. 6. All patients received informed consent to participate in a clinical trial.

\section{References}

1. Siegel RL, Miller KD, Jemal A. Cancer statistics, 2018. CA Cancer J Clin. 2018;68(1):7-30.

PMid:29313949

2. Indicators of the Oncological Service of the Republic of Kazakhstan for 2018 (Statistical and Analytical Materials), 
Almaty; 2019. p. 210.

3. Schieber M, Chandel NS. ROS function in redox signaling and oxidative stress. Curr Biol. 2014;24(10):R453-62. https://doi. org/10.1016/j.cub.2014.03.034

PMid:24845678

4. Barrera G. Oxidative stress and lipid peroxidation products in cancer progression and therapy. ISRN Oncol. 2012;2012:137289. https://doi.org/10.5402/2012/137289 PMid:23119185

5. Jang $\mathrm{HH}$. Regulation of protein degradation by proteasomes in cancer. J Cancer Prev. 2018;23(4):153-61.

\section{PMid:30671397}

6. Alnajjar KS, Sweasy JB. A new perspective on oxidation of DNA repair proteins and cancer. DNA Repair (Amst). 2019;76:60-9. https://doi.org/10.1016/j.dnarep.2019.02.006

PMid:30818170

7. Okrut IE, Kontorshchikova KN, Shakerova DA. Clinical and laboratory assessment of endothelial dysfunction and activity of free radical oxidation in breast cancer. Med Almanac. 2012;2(21):68-70.

8. Farias JW, Furtado FS, Guimarães SB, Filho AR, Vasconcelos PR. Oxidative stress parameters in women with breast cancer undergoing neoadjuvant chemotherapy and treated with nutraceutical doses of oral glutamine Acta Cir Bras. 2011;26 Suppl 1:82-7. https://doi.org/10.1590/ s0102-86502011000700017

PMid:21971664

9. Frenchman EM, Soldatkina NV, Orlovskaya LA, Dashkov AV. Some indicators of free radical processes and the antioxidant system of breast tumor tissue and its perifocal zone in various types of cancer. Tyumen Med J. 2010;3-4:92-4.

10. Rajneesh CP, Manimaran A, Sasikala KR, Adaikappan P. Lipid peroxidation and antioxidant status in patients with breast cancer. Singapore Med J. 2008;49(8):640-3.

PMid: 18756349

11. Rossner P, Terry MB, Gammon MD, Agrawal M, Zhang FF Ferris JS, et al. Plasma protein carbonyl levels and breast cancer risk. J Cell Mol Med. 2007;11(5):1138-48. https://doi. org/10.1111/j.1582-4934.2007.00097.x PMid:17979889

12. Aryal BP, Rao A. Oxidative stress and selective protein carbonylation in human breast cancer tissue. In: Proceedings of the American Association for Cancer Research Annual Meeting 2017. Washington, DC, Philadelphia, PA: AACR; 2017. https:// doi.org/10.1158/1538-7445.am2017-5486

13. Mannello F, Tonti GA, Medda V. Protein oxidation in breast microenvironment: Nipple aspirate fluid collected from breast cancer women contains increased protein carbonyl concentration. Cell Oncol. 2009;31(5):383-92. https://doi. org/10.1155/2009/545896

PMid: 19759418

14. Lee JD, Cai Q, Ou Shu X, Nechuta SJ. The role of biomarkers of oxidative stress in breast cancer risk and prognosis: A systematic review of the epidemiologic literature. J Womens Health (Larchmt). 2017;26(5):467-82. https://doi.org/10.1089/ jwh.2016.5973

PMid:28151039

15. Rabbani N, Xue M, Thornalley PJ. Dicarbonyls and glyoxalase in disease mechanisms and clinical therapeutics. Glycoconj J. 2016;33(4):513-25. https://doi.org/10.1007/s10719-016-9705-z PMid:27406712

16. Roy A, Sarker S, Upadhyay P, Pal A, Adhikary A, Jana K, et al. Methylglyoxal at metronomic doses sensitizes breast cancer cells to doxorubicin and cisplatin causing synergistic induction of programmed cell death and inhibition of stemness. Biochem Pharmacol. 2018;156:322-39. https://doi.org/10.1016/j. bcp.2018.08.041

\section{PMid:30170097}

17. Krishna KA, Pawan AR, Babu BN, Gorantla N. Anti-cancer strategies of methylglyoxal-a review. Int J Pharma Res Rev. 2015;4(7):38-42.

18. Nokin MJ, Durieux F, Bellier J, Peulen O, Uchida K, Spiegel DA, et al. Hormetic potential of methylglyoxal, a sideproduct of glycolysis, in switching tumours from growth to death. Sci Rep. 2017;7(1):11722. https://doi.org/10.1038/ s41598-017-12119-7 PMid:28916747

19. Rabbani N, Xue M, Thornalley PJ. Methylglyoxal-induced dicarbonyl stress in aging and disease: First steps towards glyoxalase 1-based treatments. Clin Sci (Lond). 2016;130(19):1677-96. https://doi.org/10.1042/cs20160025 PMid:27555612

20. Rabbani N, Xue M, Weickert MO, Thornalley PJ. Multiple roles of glyoxalase 1-mediated suppression of methylglyoxal glycation in cancer biology-Involvement in tumour suppression, tumour growth, multidrug resistance and target for chemotherapy. Semin Cancer Biol. 2018;49:83-93. https://doi.org/10.1016/j. semcancer.2017.05.006

PMid:28506645

21. Singh A, Kukreti R, Saso L, Kukreti S. Oxidative stress: A key modulator in neurodegenerative diseases. Molecules. 2019;24(8):1583. https://doi.org/10.3390/molecules24081583 PMid:31013638

22. Barrera G, Pizzimenti S, Daga M, Dianzani C, Arcaro A, Cetrangolo GP, et al. Lipid peroxidation-derived aldehydes, 4-hydroxynonenal and malondialdehyde in aging-related disorders. Antioxidants (Basel). 2018;7(8):102. https://doi. org/10.3390/antiox7080102 PMid:30061536

23. Bellier J, Nokin MJ, Lardé E, Karoyan P, Peulen O, Castronovo $\mathrm{V}$, et al. Methylglyoxal, a potent inducer of AGEs, connects between diabetes and cancer. Diabetes Res Clin Pract. 2019;148:200-11. https://doi.org/10.1016/j.diabres.2019.01.002 PMid:30664892

24. Levine RL, Garland D, Oliver CN, Amici A, Climent I, Lenz AG, et al. Determination of carbonyl content in oxidatively modified proteins. Methods Enzymol. 1990;186:464-78. https://doi. org/10.1016/0076-6879(90)86141-h PMid:1978225

25. Husna AH, Ramadhani EA, Eva DT, Yulita AF, Suhartono E. The role formation of methylglyoxal, carbonyl compound, hydrogen peroxide and advance oxidation protein product induced cadmium in ovarian rat. Int J Chem Eng Appl. 2014;5(4):319-23. https://doi.org/10.7763/ijcea.2014.v5.402

26. Goncharenko MS, Latinova AM. Method of Assessment of Peroxide Oxidation of Lipids, Lab Case No. 1; 1985.

27. Korobeinikova EN. Modification of the Determination of Lipid Peroxidation Products in Reaction with Thiobarbituric Acid Lab Case No. 7; 1989. p. 8-10.

28. Bratt $\mathrm{D}$, Jethva $\mathrm{KH}$, Patel $\mathrm{S}$, Zaveri M. Role of oxidative stress in breast cancer. Pharm pharm Sci. 2016;5(11):366-79.

29. Nourazarian AR, Kangari P, Salmaninejad A. Roles of oxidative stress in the development and progression of breast cancer. Asian Pac J Cancer Prev. 2014;5(12):4745-51. https://doi. org/10.7314/apjcp.2014.15.12.4745 PMid:24998536

30. Chakraborty S, Karmakar K, Chakravortty D. Cells producing their own nemesis: Understanding methylglyoxal metabolism. IUBMB 
Life. 2014;66(10):667-78. https://doi.org/10.1002/iub.1324

PMid:25380137

31. Nokin M, Bellier J, Durieux F, Peulen O, Rademaker G, Gabriel M, et al. Methylglyoxal, a glycolysis metabolite, triggers metastasis through MEK/ERK/SMAD1 pathway activation in breast cancer. Breast Cancer Res. 2019;21(1):1. https://doi. org/10.1186/s13058-018-1095-7

32. Prestes AS, Dos Santos MM, Ecker A, Zanini D, Schetinger MR, Rosemberg DB, et al. Evaluation of methylglyoxal toxicity in human erythrocytes, leukocytes and platelets. Toxicol Mech Methods. 2017;27(4):307-17. https://doi.org/10.1080/15376516
.2017 .1285971

PMid:28110610

33. Madian AG, Myracle AD, Diaz-Maldonado N, Rochelle NS, Janle EM, Regnier FE. Differential carbonylation of proteins as a function of in vivo oxidative stress. J Proteome Res. 2011;10(9):3959-72. https://doi.org/10.1021/pr200140x PMid:21800835

34. Lang F, Lang E, Föller M. Physiology and pathophysiology of eryptosis. Transfus Med Hemother. 2012;39(5):308-14. https:// doi.org/10.1159/000342534

PMid:23801921 